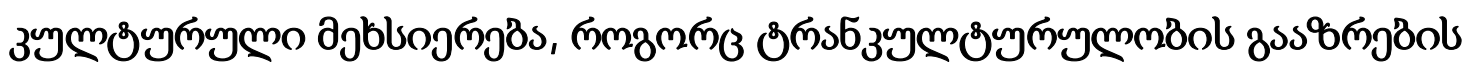 usəyssmgas
}

\author{
oscrosz3sdj ogs

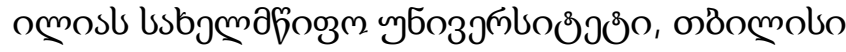

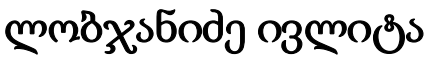

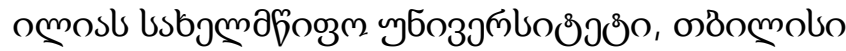

https://doi.org/10.52340/idw.2021.520

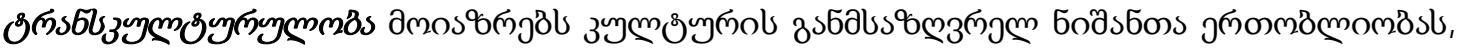

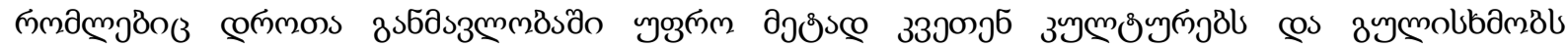

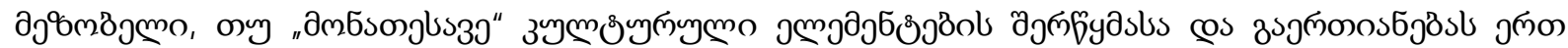

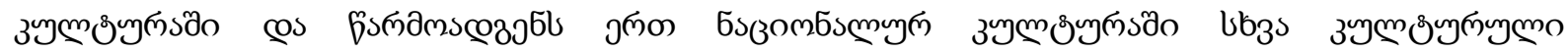

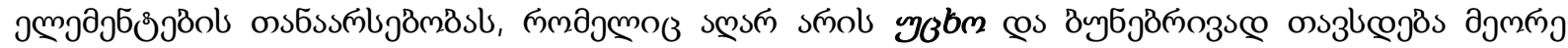

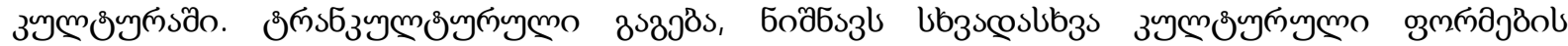

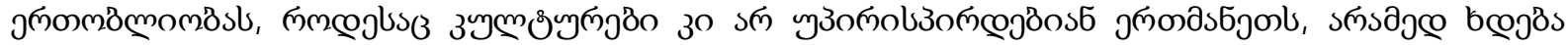

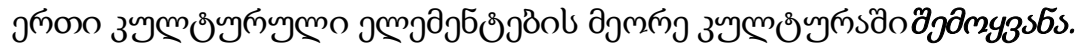

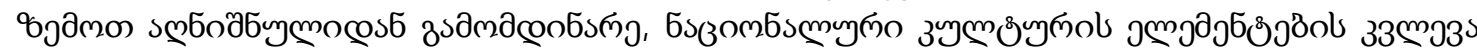

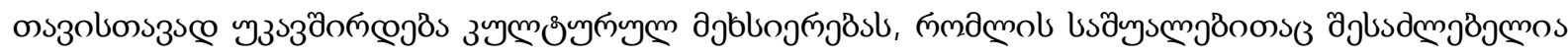

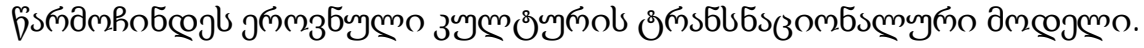

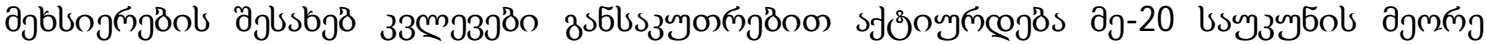

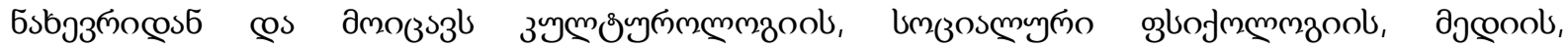

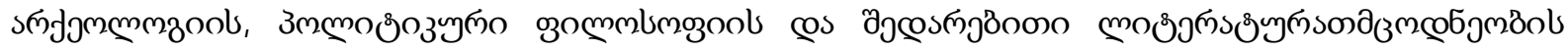

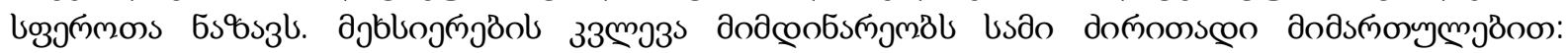

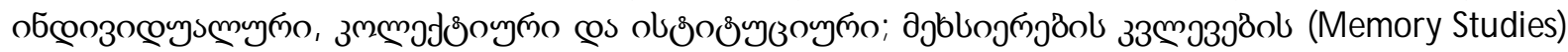

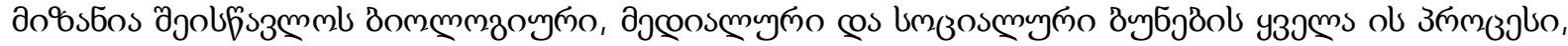

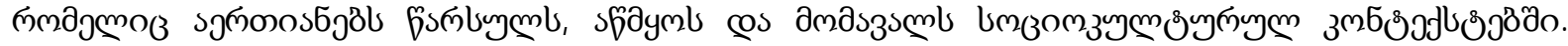

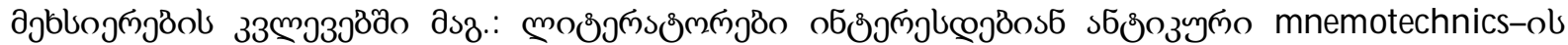

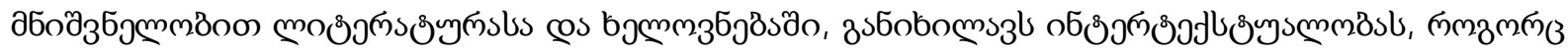

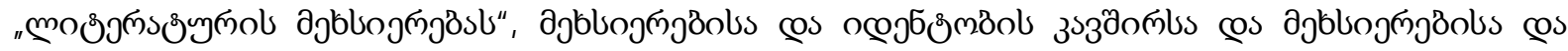

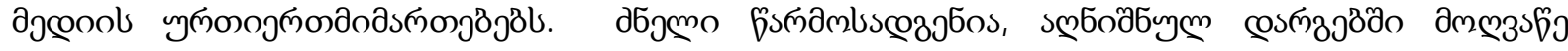

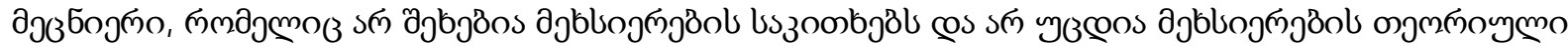

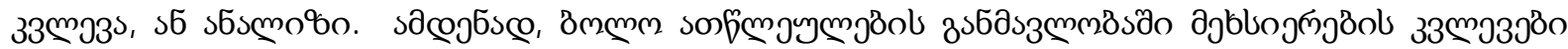

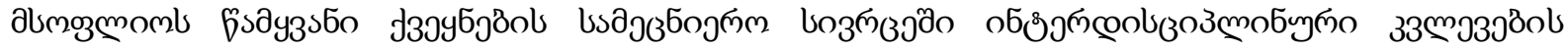
usozindmsco odiss.

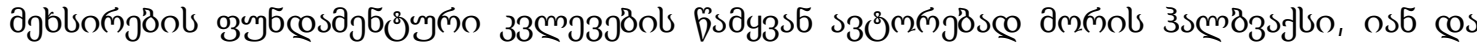

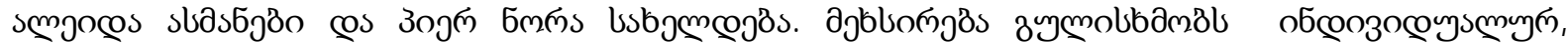

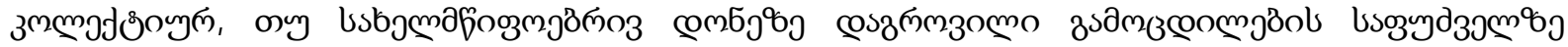

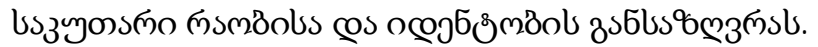

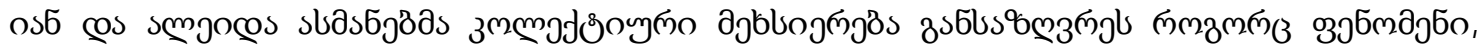

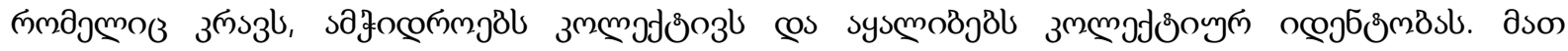

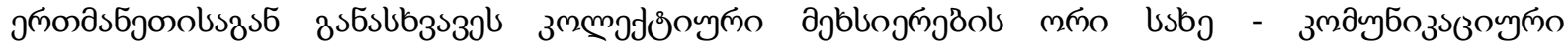

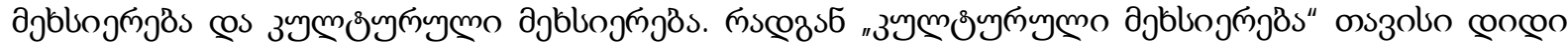




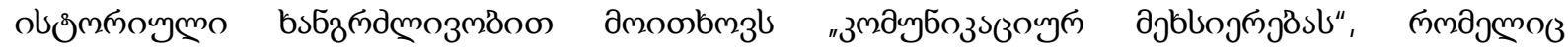

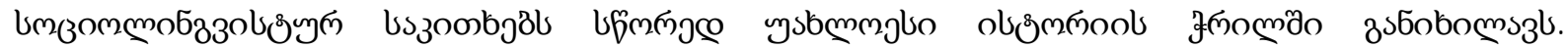

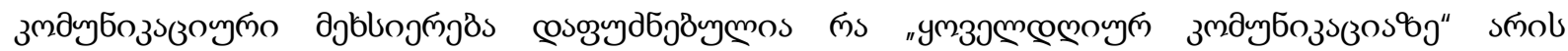

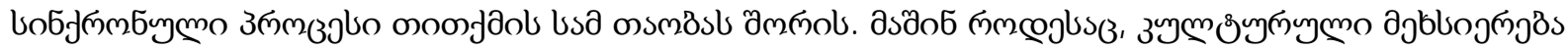

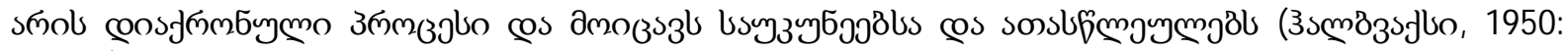
106-20).

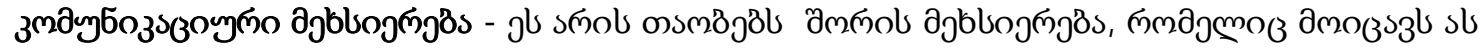

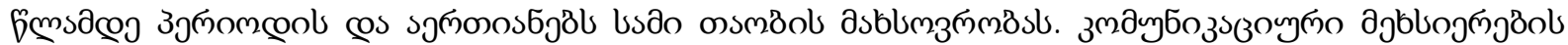

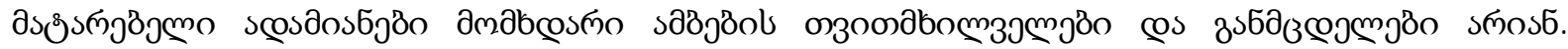

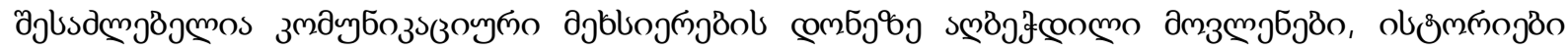

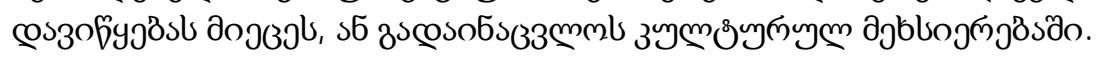

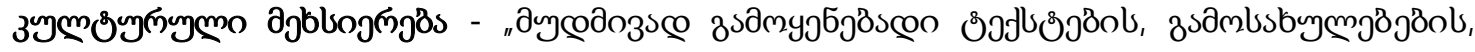

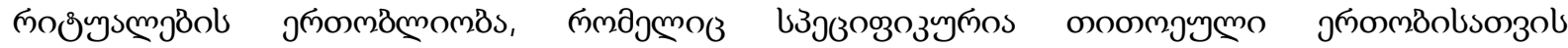

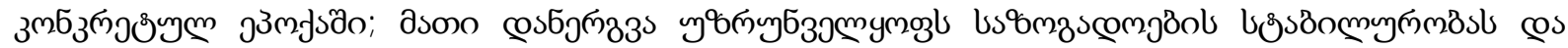

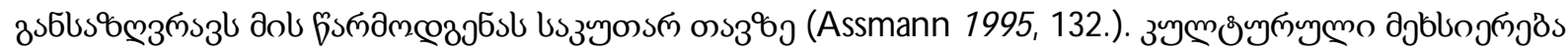

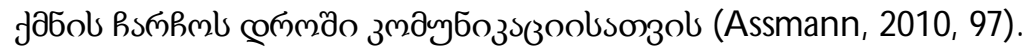

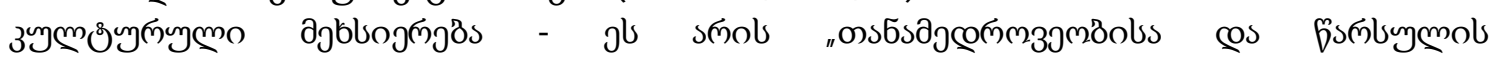

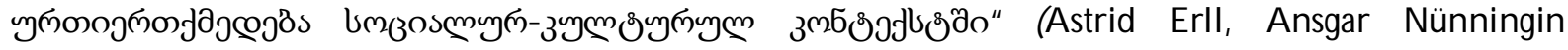

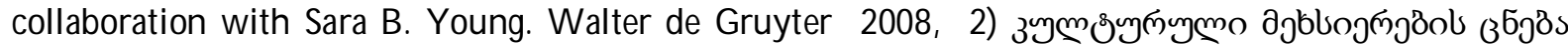

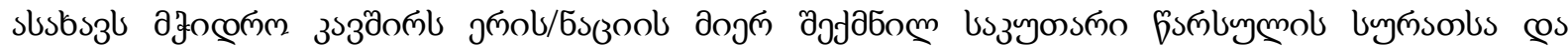

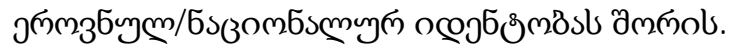

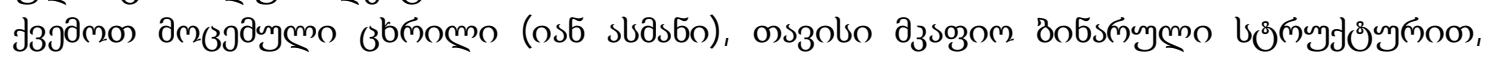

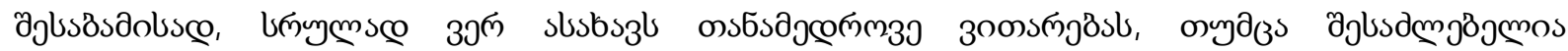

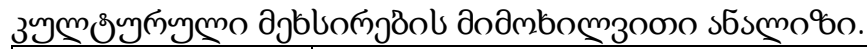

\begin{tabular}{|c|c|c|}
\hline & 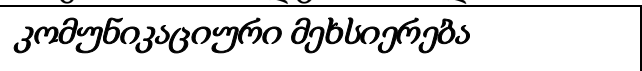 & 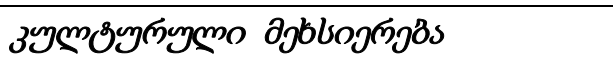 \\
\hline Dobssங̆o & 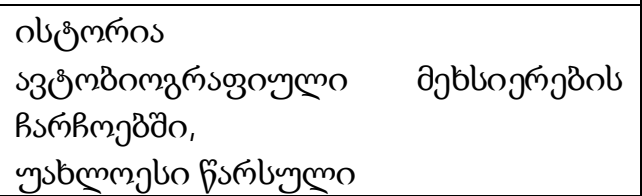 & 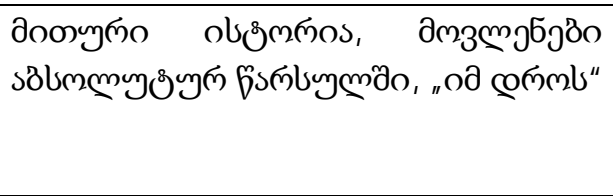 \\
\hline өмпдృன் & 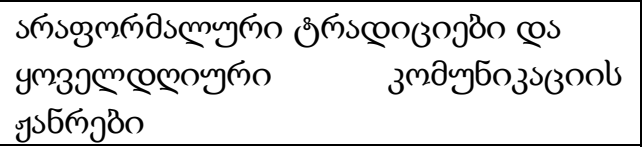 & 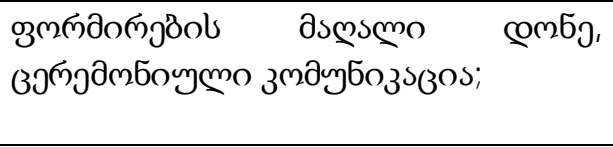 \\
\hline дgœos & 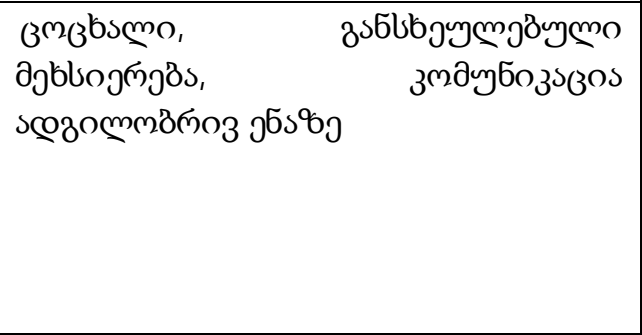 & 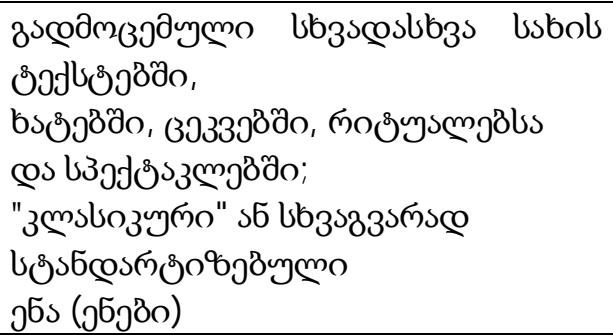 \\
\hline 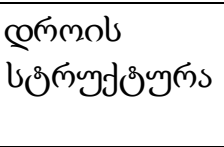 & 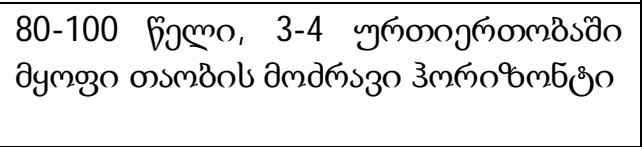 & 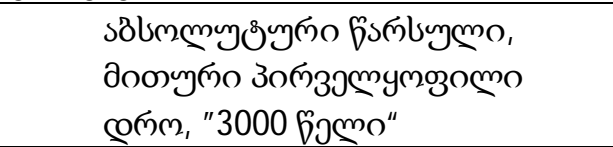 \\
\hline
\end{tabular}

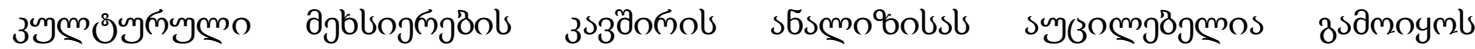

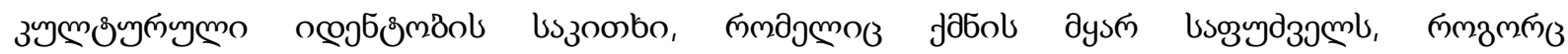

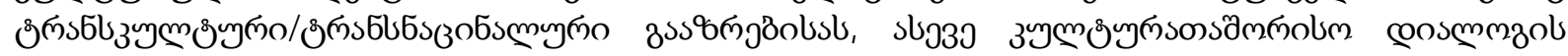

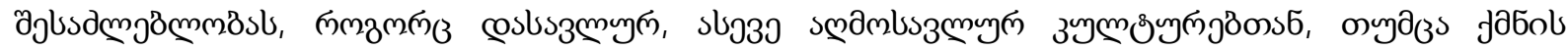

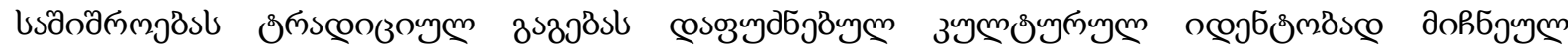




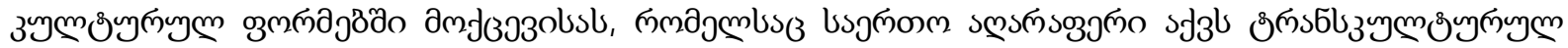
дm@gmoss.

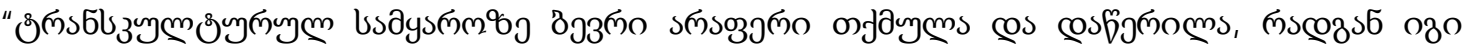

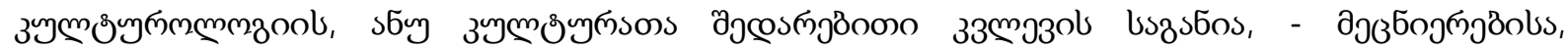

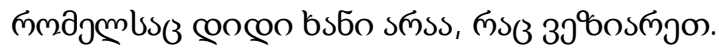

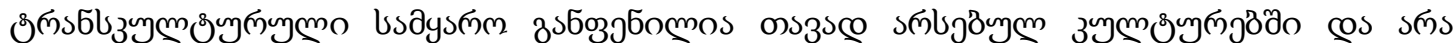

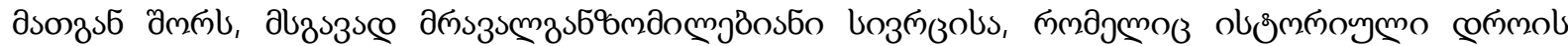

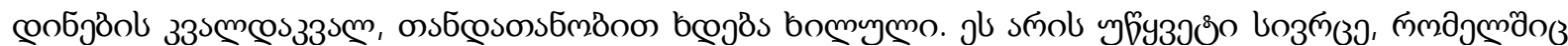

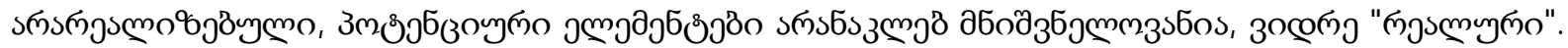

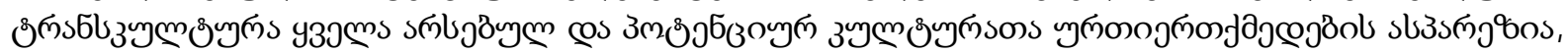

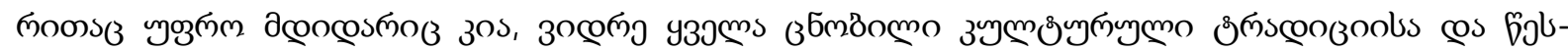

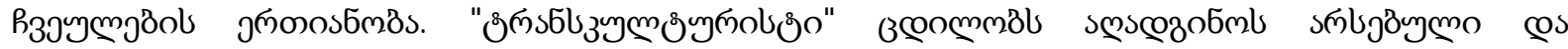

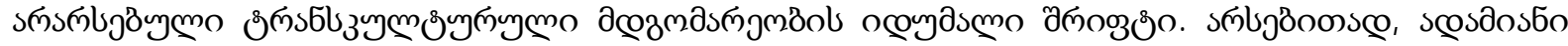

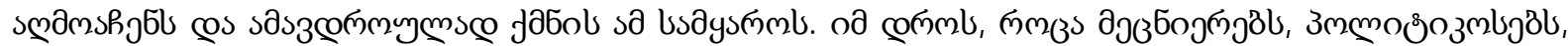

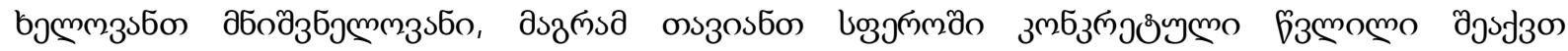

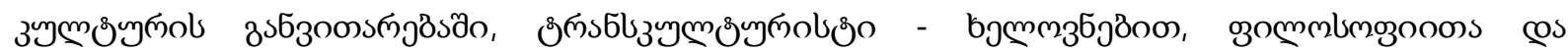

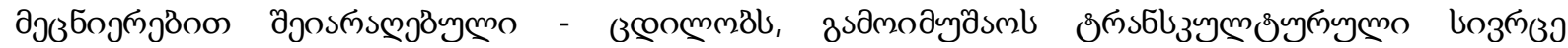

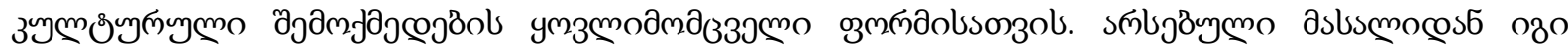

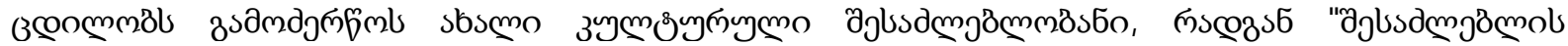

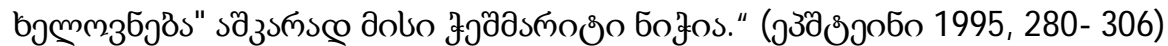

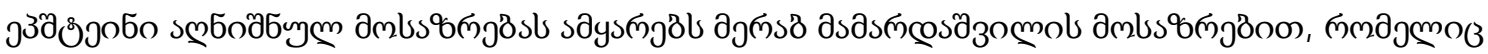

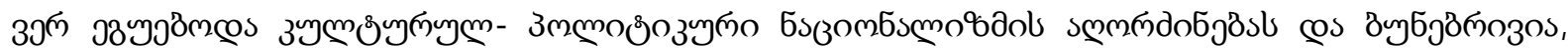

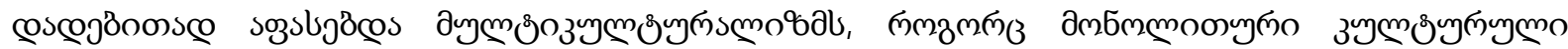

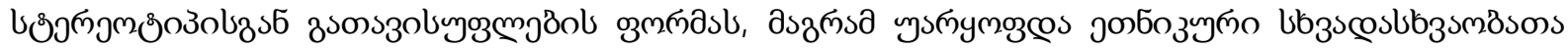

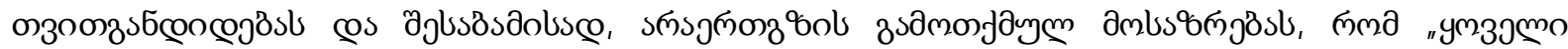

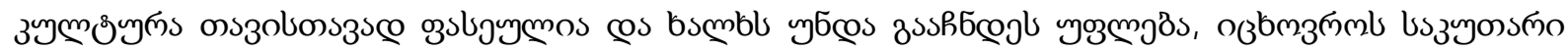

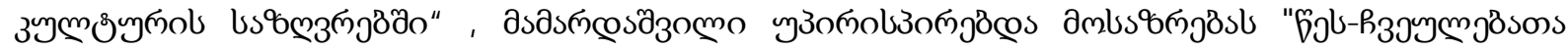

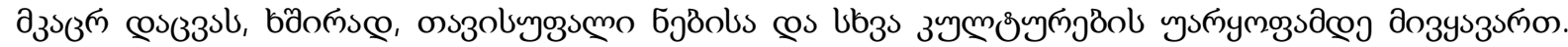
ололgl sкһ

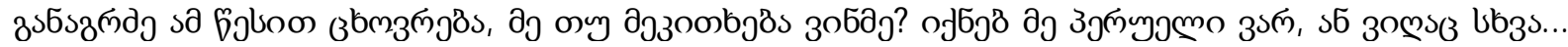

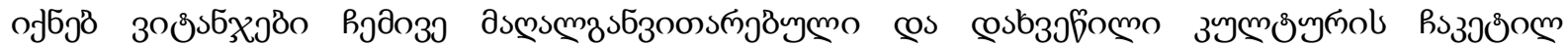
उ́msconzosoms

uobฮ์gasð̄o?

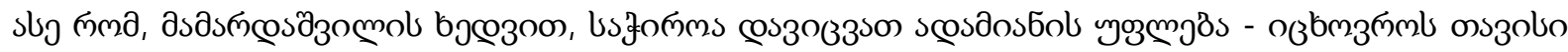

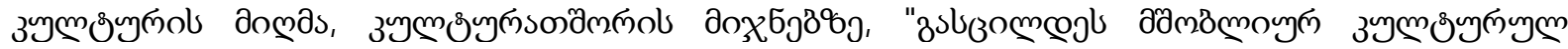

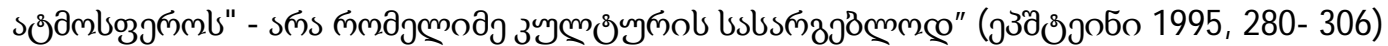

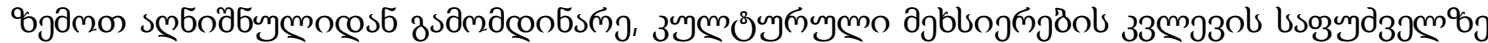

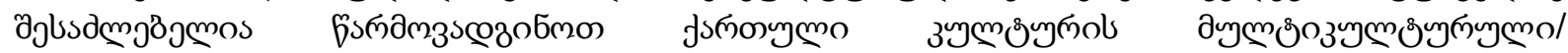

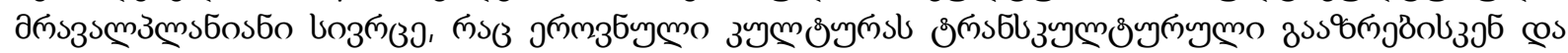

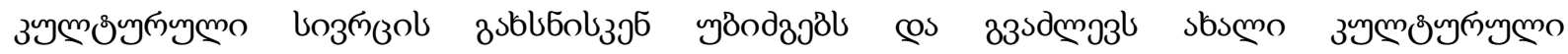

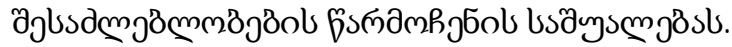

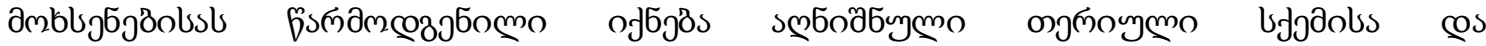

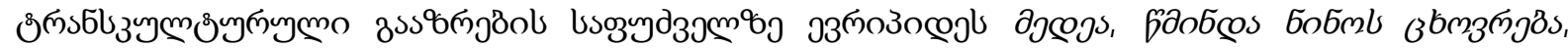
s6comosb zmoogoulbol Catharina von Georgien.

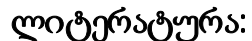

1. Assmann, Jan. Collective Memory and Cultural Identity. New German Critique 65 (1995), 33. 132.

2. Assmann, Aleida. Canon and Archive. A Companion to Cultural Memory Studies. A strid Erll, Ansgar Nunning (Eds.). De Gruyter, 2010, 33.97. 
3. Cultural Memory Studies. An Internationaland Interdisciplinary Handbook. Ed. byAstrid Erll, Ansgar Nünningin collaboration withSara B. Y oung. W al ter deGruyter. Berlin. New York. 2008, p.

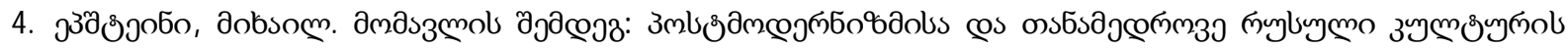

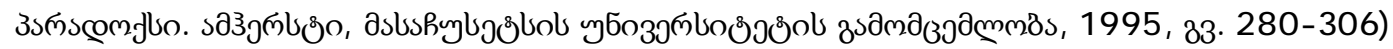

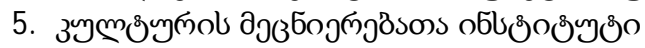
http://www.culturedialogue.com/resources/library/translations/epstein_2.shtml

6. Halbwachs, Maurice. 1950. On Collective M emory. New-Y ork; p. 106.

7. Halbwachs, M aurice. 1992. On Collective M emory. Trans. and

ed. Lewis A . Coser. Chicago: University of Chicago Press.

\title{
Cultural Memory as a Means of Understanding Transculturality
}

Talakvadze Tea

Ilia State University, Tbilisi

Lobjanidze Ivlita

Ilia State University, Tbilisi

\begin{abstract}
Memory studies have been particularly active since the second half of the 20th century and include a mix of fields of culturology, social psychology, media archeology, political philosophy, and comparative literature. Memory studies have formed the basis of both collective and individual identity studies, as well as the study of psycho-social factors in understanding traumatic memory and attempts to overcome trauma. Memory studies have activated an in-depth analysis of the construction of national and cultural identities and brought them into the context of transnational and transcultural studies.

Based on the above, the purpose of this report is to provide a transcultural understanding of national culture based on the study of cultural memory, which is primarily based on the study of national identity and the analysis of the compositional nature of common / shared myths.

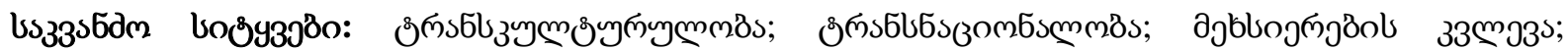

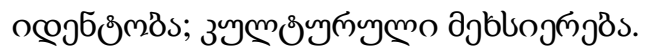

keywords: Transculture; Transnationality; Memory research; Identity; Cultural memory. 